\title{
FACTORS IN FLUENCING ACID FORMATION EFFICIENCY IN NITRIC ACID TECHNOLOGY
}

\author{
Michailo Vorozhbiyan ${ }^{1},{\text { M ykola } \text { M oroz }^{1,}{ }^{*} \text {, Svitlana Neshko }}^{1}$
}

https://doi.org/10.23939/chcht12.01.074

\begin{abstract}
The article deals with the results of the experiments and studies of nitric acid units in industry and establishes the patterns in NO oxidation under dynamic conditions in a gas phase and on the surface of phase separation considering also packing options.
\end{abstract}

Keywords: nitrous gas, absorption, nitric acid, mass exchange, oxidation.

\section{Introduction}

The main stage in the $\mathrm{HNO}_{3}$ technology is the processing of $\mathrm{NO}_{\mathrm{x}}$ into $\mathrm{HNO}_{3}$, which includes preparation of nitrous gas for absorption and further absorption of $\mathrm{NO}_{2}$ with the nitric acid solution. The efficiency of this stage influences the main parameters of the whole technology, namely the processing degree for nitric oxides, their content in the exhaust gases and concentration of the acid produced. The complex of reactions within this technology is rather complicated, not to mention the mechanisms of certain stages. The following processes are running simultaneously: oxidation of $\mathrm{NO}$ to $\mathrm{NO}_{2}$ in gas and liquid phases and on the surface of phase separation; formation of $\mathrm{HNO}_{3}$ and $\mathrm{HNO}_{2}$; when the latter decomposes a portion of NO, which needs oxidation again, is added to the liquid and gas phases. Thus, taking into account all the above mentioned, it is possible to estimate the role of NO oxidation in the whole complex of acid formation reactions.

Considerable attention should be given to the content of the nitrous gas entering the absorption column, which is important for obtaining a higher concentration of nitric acid, and also for rational use of the column volume. The lower part of the column due to higher oxidation of the gas (over $90 \%$ ) does not act as an oxidant, where there is a possibility of the oxidation reaction between $\mathrm{NO}$ and nitric acid, but occurs directly by conversing $\mathrm{NO}_{\mathrm{x}}$ into $\mathrm{HNO}_{3}$.

\footnotetext{
${ }^{1}$ State University of Railway Transport

7, Feuerbach Sq., 61050 Kharkiv, Ukraine

*morozfrostn@gmail.com

(C) Vorozhbiyan M., Moroz M., Neshko S., 2018
}

As it was established previously [1], NO oxidation plays a vital role in the nitric acid technology and also in clean-up systems for gas emission containing $\mathrm{NO}_{\mathrm{x}}$, as most of them are intended for interaction of solutions with $\mathrm{NO}_{2}$. The importance of this reaction is the reason for a great amount of studies in the field, but there is no single idea regarding the mechanism of the process, and the existing equations which describe the NO oxidation speed are controversial and do not consider all peculiarities of the process under dynamic conditions.

One should also consider that the process of NO oxidation in the nitric acid technology occurred within the volume, on the surface of phases and in the liquid phase. Part of the process within the volume, namely in a homogeneous phase, is the most essential. The authors [24] showed that during the nitrous gas processing in the absorption column, the correlation of speeds of the mentioned processes and their part in the overall reaction change. Lack of qualitative evaluation of these processes and unreconciled data in some authors' works necessitate further studies. It will allow considering the abovementioned data in calculations within appropriate ranges of NO oxidation. Bodenstein's equation [5] does not fully describe NO oxidation and, especially, in the range from 7 to $0.5 \mathrm{vol} \%$, and the mismatch between industrial and calculated data in the lower part of the column is explained by passing liquid-phase processes. It should be mentioned that if the NO content is $3 \mathrm{vol} \%$ and more, for the described conditions, the values of oxidation degree (according to M. Bodenstein [5] and others [1]) are close, but for a lower content Bodenstein's data are considerably understated. These NO concentrations accompany the nitric acid technology and gas exhaust clean-up systems. Thus the aim is to determine the ratio of NO oxidation processes in the gas, liquid and the surface phase and to evaluate the impact of the mentioned factors on the process.

\section{Experimental}

The conditions of the experiments are presented in papers [6] and [7], when selecting type and values of the 
surface (type of packing elements) considered the following: possibility to place them in the reactor of the laboratory unit, possibility to form the maximum surface with minimum packing elements mass, stability in an aggressive environment, as well as the possibility to model the process according to industrial conditions. Besides, the value of resistance, which may be created by these elements during their application in industry, has been considered.

In view of the aforesaid, the following packings have been chosen: ceramic Raschig rings $(15 \times 15 \times 2 \mathrm{~mm})$ and ceramic Berl saddles $(25 \mathrm{~mm})$.

Considering simultaneousness of oxidation and absorption processes in the $\mathrm{HNO}_{3}$ production, in order to identically estimate the impact of kinetic energy of the gas flow, the authors used the criterion $F$-factor, which reflects consistency of kinetic energy of gas and is defined according to the equation:

$$
F=w \cdot \sqrt{P}
$$

where $w$ is the linear speed of the gas, $\mathrm{m} / \mathrm{s} ; P$ is the total pressure in the unit, $\mathrm{MPa}$

The absorption process is undoubtedly influenced by such factors as oxidation of the nitrous gas $(\alpha)$, the $\mathrm{NO} /\left(\mathrm{NO}+\mathrm{NO}_{2}\right)$ ratio on the preparation to absorption stage as well as during the whole process of acid formation in the column.

In order to compare processes running in the presence of an extended surface and without it, on the basis of the obtained data, the concept of the NO oxidation degree increase $\left(\Delta \alpha_{h o m}\right)$ and the specific increase $\frac{\Delta \alpha}{\alpha}$ was introduced. This made it possible to evaluate influence of all elements on the process of heterogeneous NO oxidation.

\section{Results and Discussion}

By estimating the efficiency of processes in an absorption column of a production scheme (unified acid line schemes in Ukraine), which work under the pressure of $0.75 \mathrm{MPa}$, it should be noted that concentration of the acid produced at all production plants accounts for approximately $57 \mathrm{wt} \%$, and the $\mathrm{NO}_{\mathrm{x}}$ content after the absorption column ranges within $0.11-0.14$ vol \% .

We have reasons to consider that these factors do not comply with capacities of the existing production units. To confirm our concept we conducted a complex of tests in a production absorption column. It allowed us to establish that the efficient $\mathrm{NO}_{\mathrm{x}}$ processing into $\mathrm{HNO}_{3}$ is running up to the $20^{\text {th }}$ mass exchange plate at the maximum, which is shown in Fig. 1. The other part of the column ( 25 plates approximately) is not efficient.
Along with experimental data we calculated the equilibrium and actual absorption degrees and acid formation values in the absorption column. For this we used the algorithm for the absorption column calculation developed earlier [8]. The dependency of acid formation on the number of mass exchange plates is presented in Fig. 2.

By analyzing the results obtained one can confirm the irregularity of the $\mathrm{NO}_{\mathrm{x}}$ absorption process along the whole absorption column, which undoubtedly influences major characteristics of the absorption process and the technology itself. The area of intensive acid formation includes plates from 1 to 10 , and further its value decreases. Besides, it is also confirmed by reduction in the driving force of the process $(\Delta P)$ after the $12^{\text {th }}$ plate. By considering the values of the equilibrium absorption stage $\left(y^{*}\right)$ along the height of the column and comparing it with the actual absorption level $(Y)$, one can find potential for its increase along the whole height of the column.

The experimental and theoretical data obtained make it possible to conclude about the lack of process intensity in the column and hidden potential.

Influence of hydrodynamics on the process can be regarded from two points: direct impact of a linear speed of the gas flow (other parameters being equal) and an impact of the $F$-factor on the speed of the process. It should be noted that besides the change in the hydrodynamic situation in the unit when the linear speed changes (increases) the time of component contact decreases (reaction time), which considerably decreases the NO oxidation degree. In this case the time was constant; dependency of oxidation degree on the $F$-factor is given in Fig. 3.

These data made it possible to consider the hydrodynamic factor in calculations of the NO oxidation degree and present the equation for calculation, from which we can conclude that when the $F$-factor increases the oxidation degree increases. To estimate the direct influence of hydrodynamics on the process the research was carried out with constant partial pressures of the components and oxidation time. It allows us to conclude about the vital role of hydrodynamics for the NO oxidation process, but appropriate increase in the $F$-factor is justified in the range of $0.1-0.3$. The given hydrodynamics in the reactor can be obtained, i.e. a given value of the $F$-factor is possible due to various values of pressure and linear speed, according to peculiarities of a certain technology. The results of these studies are important in terms of justification relations oxygen oxidation of $\mathrm{NO}$ to $\mathrm{NO}_{2}$ under dynamic conditions in different phases, including the surface distribution phase and selection of technological parameters driving the process. 


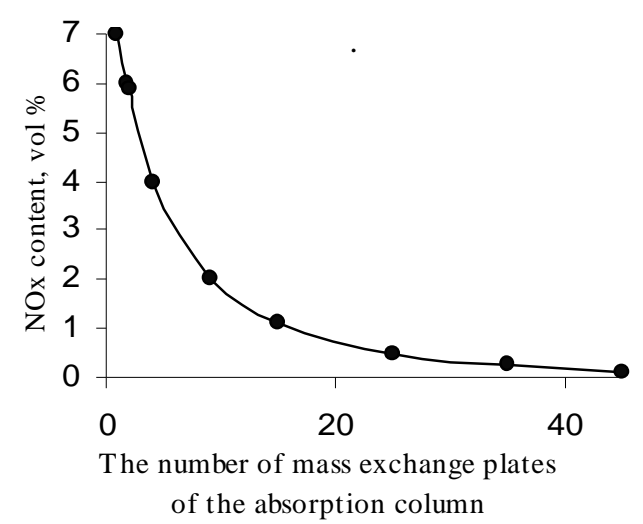

Fig. 1. Dependency of the NOx content in the nitrous gas on the number of mass exchange plates

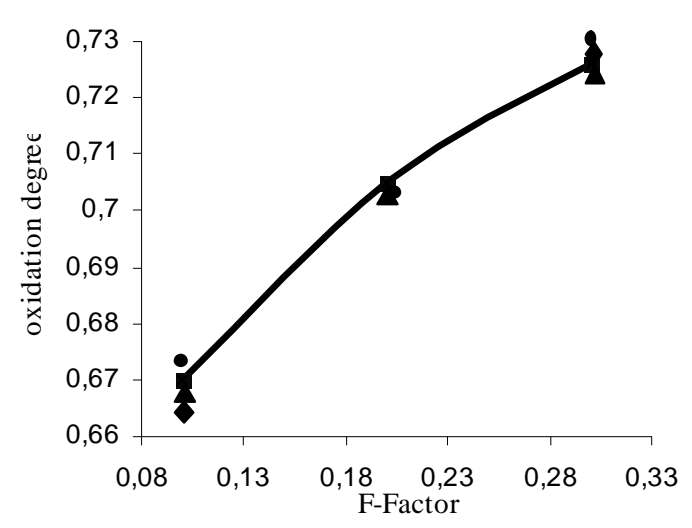

Fig. 3. NO oxidation degree $v s$. $F$-factor at $P_{\mathrm{NO}}=0.008 \mathrm{MPa} ; P_{\mathrm{O} 2}=0.005 \mathrm{MPa} ; T=293 \mathrm{~K} ; \tau=3 \mathrm{~s}$.

Pressure, MPa: $0.3(\bullet) ; 0.5(\bullet) ; 0.7(<)$ and $10(\bullet)$

Thus, the authors obtained the possibility to consider dynamic conditions of the NO oxidation process including the $\mathrm{HNO}_{3}$ production. The equation for calculation of the process speed of homogenous NO oxidation in dynamic conditions is as follows:

$$
r_{\text {hom }}=-\frac{d P_{N O}}{d \tau}=K_{\text {hom }} \cdot P_{N O}^{1.69} \cdot P_{O_{2}}^{0.80}
$$

where $K_{\mathrm{hom}}=39.6 \cdot e^{\frac{5071.4}{R T}} \cdot F^{0.21}$ is the apparent constant of speed of homogenous NO oxidation in dynamic conditions; $5071.4 \mathrm{~J} / \mathrm{mol}$ is the apparent energy of reaction in dynamic conditions and the temperature interval from 293 to $333 \mathrm{~K}$.

Differences in orders of the NO oxidation reaction by components from those accepted in Bodenstein's equation ( $3^{\text {rd }}$ order) can be explained by the fact that this reaction does not run in a kinetic zone only, but in the transition one as well; the speed constant of the reaction depends not only on the temperature, but on the $F$-factor. This fact confirms again heterogeneous nature of the reaction and puts grounds for understanding homogeneous

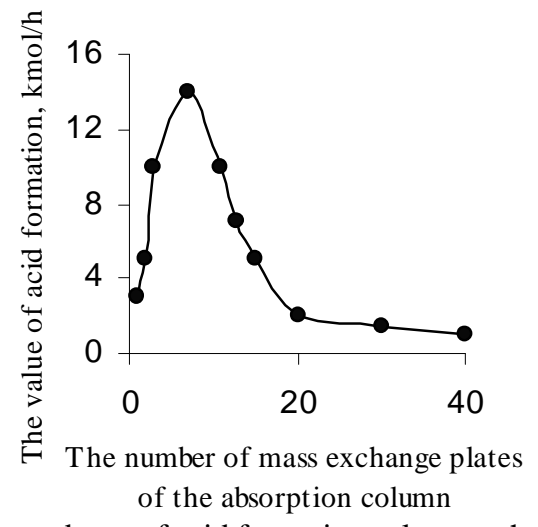

Fig. 2. Dependency of acid formation values on the number of mass exchange plates

and heterogeneous character of the reaction. Most likely, under dynamic conditions the process runs in the transition zone, and when the linear speed grows the processes of components diffusion play a very important role. Besides, when the linear speed grows the coefficient of turbulent diffusion in the gas flow near walls of the reactor (so called wall effect) grows considerably and, as is shown below, the relation between the internal surface of the reactor and its volume $S / V, \mathrm{~m}^{2} / \mathrm{m}^{3}$ plays a certain role. According to V. Ramm, the coefficient of turbulent diffusion exceeds the coefficient of molecular diffusion by 100 times and more and depends on hydrodynamics of the gas flow.

Existence of heterogeneous process during NO oxidation is established by many authors, and its quality evaluation is also given. The authors' purpose was to give qualitative evaluation to part of heterogeneous process depending on surfaces of the reactor elements and other technologic parameters during $\mathrm{NO}$ oxidation.

Part of NO oxidation on the surface in comparison with the process running within the volume, can be evaluated by comparing the results obtained within one series of experiments with those obtained earlier, but without packings. Thus, the role of heterogeneous process has been established, which increases when NO concentration in the gas and with the presence of packings of large specific surface decreases (Fig. 4).

The change in dependency of the oxidation degree on the height of the packing layer when pressure grows can also be noted: the lower the pressure in reactor, the higher the influence of the height of the packing layer on the process. Presence of packings in the reactor decreases the free volume and, therefore, the general time when the gas is in the reaction zone. Despite this, an increased oxidation degree in every case is observed, which testifies the heterogeneous character of the oxidation process. The impact of the height of the packing layer on the change of a relative increase in NO oxidation degree is presented in Fig. 5. 
The dependencies obtained testify to the fact that the lower pressure, the higher is the specific oxidation increase. It can be explained by more considerable impact of pressure on homogenous NO oxidation than on the heterogeneous one.

The highest impact of the surface of the packings is observed in the area of the low partial pressures of $\mathrm{NO}_{\mathrm{x}}$ (Fig. 6), and the height of the packing layer should be increased to a certain value. The creation on the surface of the cap higher NO concentrations in comparison with the gas flow leads to a faster oxidation reaction and higher oxidation degree in heterogeneous conditions. The change in the specific surface of the reactor $S / V\left(\mathrm{~m}^{2} / \mathrm{m}^{3}\right)$ influences the hydrodynamic situation in the unit, especially in the zone near the unit walls. Simultaneously, when the linear speed of the gas flow increases the turbulization of the latter grows (the $F$-factor, Re).

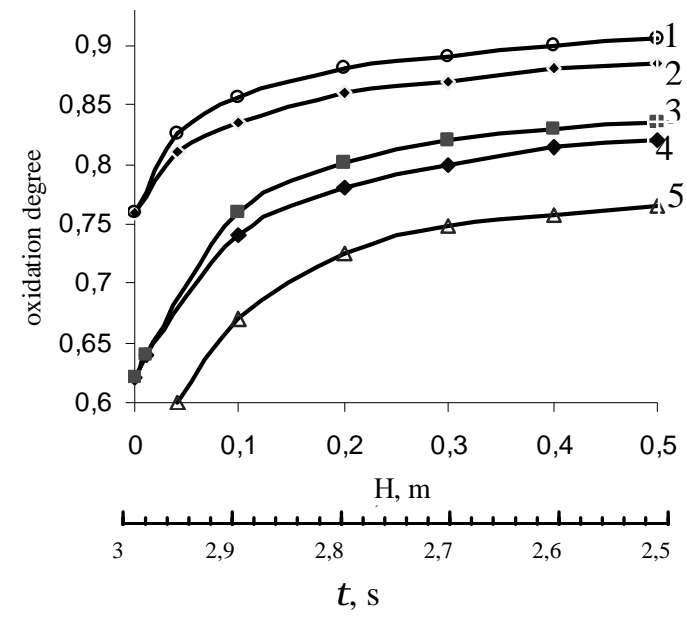

Fig. 4. NO oxidation degree $v s$. packing layer height at $T=293 \mathrm{~K}$; $C_{\mathrm{O} 2}=5 \mathrm{vol} \% ; w=0.3 \mathrm{~m} / \mathrm{s}$; pressures of $0.7 \mathrm{MPa}(1-4)$ and $0.3 \mathrm{MPa}(5)$.

Berl saddles $(25 \mathrm{~mm})(1,3)$; Raschig rings $(15 \times 15 \times 2 \mathrm{~mm})$ $(2,4,5) . C_{\mathrm{NO}}$, vol \%: $1(1,2) ; 3(3-5)$

Fig. 6. Specific oxidation degree increase $v s$. NO content in the gas at $P=0.7 \mathrm{MPa} ; T=293 \mathrm{~K} ; C_{\mathrm{O} 2}=5 \mathrm{vol} \% ; w=0.3 \mathrm{~m} / \mathrm{s}$; $H=0.4 \mathrm{~m} ; \tau=2.6 \mathrm{~s}$. Berl saddles $(25 \mathrm{~mm})(1)$ and Raschig rings $(15 \times 15 \times 2 \mathrm{~mm})(2)$
The increase in the degree of NO oxidation due to the heterogeneous process is provided by amount of surfaces in the reactor, the characteristics of which are $H$ and $S_{s p}$. The increase of $\Delta \alpha$ accounts for the difference between $\alpha_{h e t}$. and $\alpha_{h o m}$, where $\alpha_{h e t}$ is the oxidation degree in the presence of packing. The impact of different factors on $\alpha_{h o m}$ has been studied earlier and is appropriate to this model. $\Delta \alpha=-0.49081 \cdot H^{0.3} \cdot\left(1-0.2478 \cdot S_{s p}^{0.4}\right) \cdot\left(1-\alpha_{\text {hom }}\right)$. Provided that the NO oxidation reaction with oxygen to $\mathrm{NO}_{2}$ occurs not just in a kinetic zone, but in a transition one (which is more natural), it is possible to explain the impact of diffusion on the process and, therefore, the impact of the reactor walls and the values of the packing specific surface.

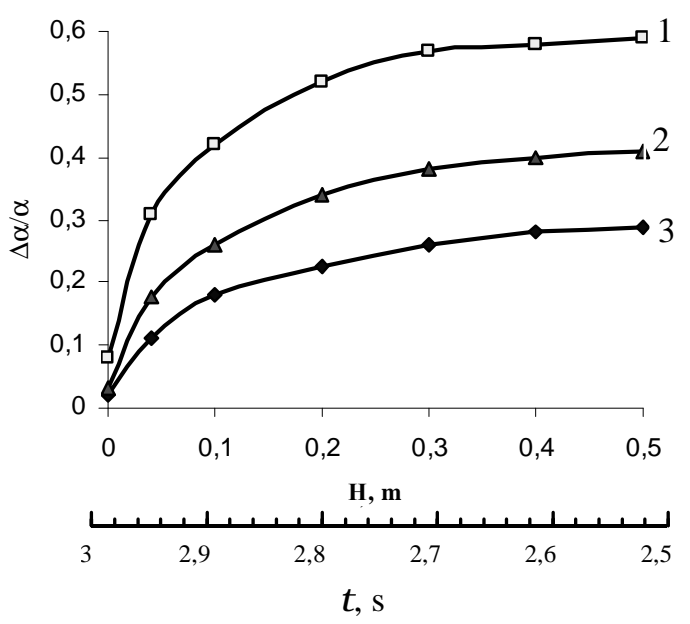

Fig. 5. Specific oxidation degree increase $v$ s. packing layer height at $T=293 \mathrm{~K} ; C_{\mathrm{NO}}=1 \mathrm{vol} \% ; C_{\mathrm{O} 2}=5 \mathrm{vol} \% ; w=0.3 \mathrm{~m} / \mathrm{s}$; Presuure, MPa: 0.7 (1); 0.5 (2) and 0.3 (3)

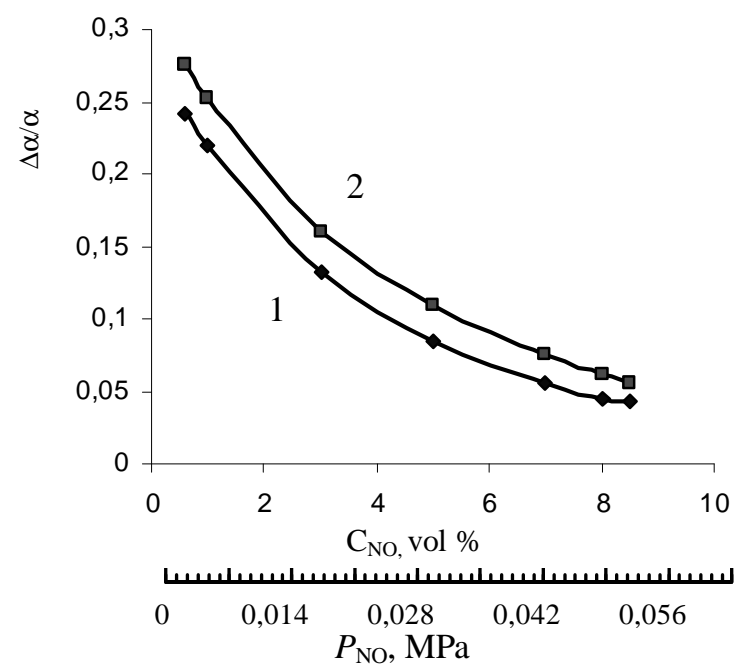




\section{Conclusions}

The results of the experiments conducted in laboratories and in production demonstrated the impact of hydrodynamic factors, surface of reactor walls and packings located in the reactor on the oxidation degree. The impact of these factors depends mostly on the NO content in the gas. When the NO content in the nitrous gas is lower, the speed decrease for homogenous oxidation is more considerable than that for heterogeneous oxidation.

Taking into account all constituents of $\mathrm{NO}$ oxidation occurring along the height of the absorption column, namely homogeneous one, heterogeneous one, the one occurring on the surface of phase separation (solid-gas-liquid, liquid gaseous), as well as the one occurring directly in a liquid phase, it is possible to regulate the proportion of these constituents by placing packings on the mass exchange plates and to obtain the maximum oxidation degree in every zone, which obviously will contribute to a higher degree of the $\mathrm{NO}_{\mathrm{x}}$ to $\mathrm{HNO}_{3}$ processing and considerably decrease absorption exhaust clean-up costs.

\section{References}

[1] Shapka O., Vorozhbyian M., Kostyrkin O.: UkrDAZT. Zbirn. nauk. prats, 2003, 56, 142.
[2] Romankov P., Frolov V., Flisyuk O.: Massoobmennyie Protsessy Khimicheskoi Tehnologii. Khimizdat, Sankt-Peterburg 2011.

[3] Sarilov M., Tyaguschev P.: Mezhdunar. Zhurn. Eksperimen. Obrazov., 2016, 6, 122.

[4] Kuzhevatov S., Kutsenko E., Gleyzer I., Senyavin V.: Pat. RU 2286839, Publ. Dec. 10, 2006.

[5] Zabolotskiy A.: Zhurn. Obschey Khimii, 1950, 26, 1392.

[6] Vorozhbiian M., Kostyrkin O., Kovalenko T.: UkrDAZT. Zbirn. nauk. prats, 2003, 56, 136.

[7] Vorozhbiyan M., Kobzev O., Markova N.: Vestnik NTU "Kharkov Politechnic Institute", 2001, 14, 277.

[8] Vorozhbiyan M., Moroz N., Garmash B. et al.: Vestnik NTU "Kharkov Politechnic Institute", 2010, 13, 52.

Received: February 06, 2017 / Revised: March 28, 2017 / Accepted: May 25, 2017

\section{ЧИННИКИ, ЩО ВПЛИВАЮТЬ НА ЕФЕКТИВНІСТЬ КИСЛОТОУТВОРЕННЯ В ТЕХНОЛОГІї НІТРАТНОЇ КИСЛОТИ}

Анотація. На підставі експериментальних досліджень та обстежень агрегатів виробництва нітратної кислоти в промислових умовах встановлені закономірності прочесу протікання окиснення $\mathrm{NO}$ за динамічних умов в газовій фазі та на поверхні розподілу фаз, в тому числі в присутності насадкових елементів.

Ключові слова: нітрозний газ, абсорбція, нітратна кислота, масообмін, окиснення. 